\title{
Rotary tillage effects on some selected physical properties of fine textured soil in wetland rice cultivation in Malaysia
}

\begin{abstract}
The aim of this study was to investigate the effects of short-term repeated passes tillage operations on bulk density, soil penetration resistance, soil porosity and the moisture of a clay loam soil of Malaysia. A field experiment for three seasons was conducted at Sungai Burong Tanjung Karang Kuala Selangor, Malaysia to study treatments consisting of (I) no-tillage NT (II) first tillage FT (III) second tillage (ST), (IV) third tillage (TT) operations. The soil bulk density, soil penetrometer resistance, pore distribution, and moisture content characteristics were determined before and after for each of the three tillage. The penetration resistance was determined at the depths of $0-80 \mathrm{~cm}$ while the soil moisture was determined on the surface $(0-20 \mathrm{~cm})$. These properties were determined directly before and after tillage operations. All the tillage operations were significantly different in their effects on soil bulk density and soil penetration resistance. The soil bulk density decreased with the degree of soil manipulation after first and third tillage and increased after second tillage, with NT having the highest mean bulk density $1.04,0.95$ and $1.03 \mathrm{~g} / \mathrm{cm} 3$ while TT having the least $0.84,0.83$ and $0.72 \mathrm{~g} / \mathrm{cm} 3$ for $1 \mathrm{st}, 2 \mathrm{nd}$ and $3 \mathrm{rd}$ season respectively. The soil penetration resistance decreased due to tillage operation, with NT also having the highest resistance of $1.69 \mathrm{MPa}$ and 1.44 Mpa in hardpan during 1st and 2nd season and the lowest PR was 0.09, 0.17 and 0.21 Mpa at TT in 1st, 2nd and 3rd season. Highest mean porosity was 0.68 in 2nd season at TT and the lowest mean porosity was 0.36 in 3rd season at NT. The lowest volumetric moisture content was at ST 0.26 and 0.27 in 1 st and 2nd season at ST, and the highest was at TT 0.56, 0.57 and 0.68 at TT in 1st, 2nd and 3rd season respectively. The soil particle density was increased after three tillage operation. The highest increase (23.73\%) was noted in FT 2nd season and the minimum was in TT in 1 st season $(6.04 \%)$ while it decreased in ST during the three seasons.
\end{abstract}

Keyword: Cone index; Penetration resistance; Tillage; Clay loam soil; Bulk density; Rotary; Porosity 